\title{
Clinical application of arthroscopy-assisted minimally invasive therapy in Chinese elderly with type III Pilon fracture
}

\section{Peiming Liu \\ Yong Guo \\ Ying Wen \\ Wei Wang}

The Eleventh Department of Orthopaedics, The Fifth Hospital of Harbin, Harbin, China
Correspondence: Wei Wang

The Eleventh Department of Orthopaedics, The Fifth Hospital of Harbin, 27 Health Road, Harbin I50040, China

Email tiantian229_229@163.com
This article was published in the following Dove Press journal:

Clinical Interventions in Aging

\begin{abstract}
Objective: Pilon fracture is so complex that its therapy poses a great challenge to surgeons. Few studies have compared arthroscopy-assisted minimally invasive therapy and external fixation combined with limited internal fixation (EFLIF), and an optimal choice of surgical therapy remains unclear in patients with type III Pilon fracture. Moreover, to our knowledge, very few studies have specifically evaluated arthroscopy-assisted minimally invasive therapy in Chinese elderly with type III Pilon fracture. The current study was performed to observe the clinical application of arthroscopy-assisted minimally invasive therapy, compared with EFLIF, in Chinese elderly with type III Pilon fracture.

Methods: There were 230 Chinese elderly with type III Pilon fracture assigned to undergo EFLIF (group A, $n=115$ ) or arthroscopy-assisted minimally invasive therapy (group B, $n=115$ ), and followed up for 1 year after surgery.

Results: Age, sex, causes, sides and types of Pilon fractures were not different between the two groups ( $P>0.05$ for all). Compared with EFLIF, arthroscopy-assisted minimally invasive therapy achieved a better reduction result, bone union and Mazur system $(P<0.05$ for all). Patient satisfaction, screw loosening and infection prevalence were not different between the two groups ( $P>0.05$ for all). There was no skin necrosis in the two groups. Traumatic arthritis had a significantly lower prevalence in participants with arthroscopy-assisted minimally invasive therapy than EFLIF ( $P<0.05$ for all).
\end{abstract}

Conclusion: Compared with EFLIF, arthroscopy-assisted minimally invasive therapy for type III Pilon fracture significantly improved reduction result, bone union and functional status, and decreased traumatic arthritis, demonstrating that arthroscopy-assisted minimally invasive therapy is an optimal choice for type III Pilon fracture in Chinese elderly.

Keywords: arthroscopy-assisted minimally invasive therapy, Chinese elderly, external fixation combined with limited internal fixation, type III Pilon fracture

\section{Introduction}

Pilon fracture occurs in distal tibia, and affects weight-loading on the articular surface and metaphysis. It accounts for about $1 \%$ of all lower limb fractures and $3 \%-10 \%$ of tibial fractures, with high complication rates $(11.4 \%-54 \%) .{ }^{1}$ Pilon fracture often leads to severe injuries of articular cartilage and soft tissue, and different degrees of metaphyseal compression and comminution. ${ }^{2,3}$ It usually results from axial load and shear force caused by falling accidents, physical sports or traffic accidents. ${ }^{4}$ Soft tissue with poor circulation, and high risk of different complications make Pilon fracture difficult to treat with a poor prognosis. Its previously used surgical therapies include open reduction and internal fixation (ORIF) and external fixation combined with limited internal fixation 
(EFLIF). ORIF can achieve anatomical reconstruction of the articular surface without repairing soft tissue. ${ }^{5}$ EFLIF can protect soft tissue, but result in poor reconstruction of the articular surface and high risk of traumatic arthritis. ${ }^{6}$ In spite of showing no advantage over ORIF in treating Type I and II Pilon fractures without soft-tissue injury, EFLIF has been recommended as a standard therapy for Type III Pilon fracture with severe soft-tissue injury. ${ }^{7}$

Based on the principle of biological osteosynthesis, arthroscopy-assisted minimally invasive therapy can protect soft tissue to improve blood supply, and apply indirect reduction to promote bone union. ${ }^{8}$ Few studies have compared arthroscopy-assisted minimally invasive therapy and EFLIF, and an optimal choice of surgical therapy remains unclear in patients with type III Pilon fracture. Moreover, to our knowledge, very few studies have specifically evaluated arthroscopy-assisted minimally invasive therapy in Chinese elderly with type III Pilon fracture. Therefore, the current study was performed to observe the clinical application of arthroscopyassisted minimally invasive therapy, compared with EFLIF, in Chinese elderly with type III Pilon fracture.

\section{Methods}

\section{Study participants}

From January 2010 to January 2016, 230 Chinese elderly with type III Pilon fracture in our department of orthopedics met the inclusion criteria: 1) Pilon fracture (different degree of metaphyseal compression and comminution, unstable fracture height, and primary injury of articular cartilage) based on trauma history, physical examination, plain film and computed tomography; ${ }^{9,10} 2$ ) type III (comminuted intra-articular fracture with displacement) based on Rüedi-Allgöer system; ${ }^{11}$ and 3 ) $\geq 60$ years. Patients were excluded if they had the following: 1) pathological fracture; 2) cancer, diabetes or immunodeficiency; 3) femoral neck fracture; or 4) spinal cord injury. All patients were assigned to undergo EFLIF (group A, n=115) or arthroscopy-assisted minimally invasive therapy (group $\mathrm{B}, \mathrm{n}=115$ ). The current study was approved by the Ethics Committee of The Fifth Hospital of Harbin. Informed written consent was provided by each participant.

\section{Preoperative preparation}

Patient information was obtained and physical examination was performed before surgery. Plain film and computed tomography were routinely performed, and separately evaluated by two experienced radiologists. Longitudinal traction and plaster slab were performed to reconstruct fix ankle axis. Mannitol was used for at least 5 days to alleviate local swelling.

\section{Operative therapy}

All surgeries were performed by experienced surgeons. EFLIF has been commonly used in clinical practice and previously described by Marin et al. ${ }^{12}$ As described by Luo et al, arthroscopy-assisted minimally invasive therapy was performed in the following steps: ${ }^{13} 1$ ) broken end was exposed through one posterolateral fibular incision, and plate fixation was performed after reduction under direct vision; 2) external fixator was used to achieve indirect reduction, protect soft tissue and reconstruct limb length; 3) two sides of distal tibia were unfolded to obtain adequate space in the ankle joint available for arthroscopy; 4) arthroscopic camera and instrument (Stryker Corporation, Kalamazoo, MI, USA) were inserted into the ankle through two incisions at the front of the ankle for observation and reduction, and blood clots and bone scraps were cleared under arthroscopy. One longitudinal tibial incision was made near the joint surface, and broken bone was exposed after blunt dissection. Percutaneous reduction was performed with one fascia stripper by leverage, and the articular surface was smoothed through picking with one hook; 5) autogenic ilium packing traction and reduction were performed through one anterior tibial incision, and the remaining bone defect in the metaphysis was subjected to adequate bone grafting; 6) one minimally invasive plate was placed between fascia and periosteum, and three to four screws were used to fix the fracture. Internal fixation was performed with lock plates and cannulated compression screws (Trauson, Changzhou, Jiangsu, China), and external fixation was performed with external fixators (Trauson).

\section{Postoperative management}

Participants were followed up for 1 year after surgery. Reduction results were categorized as anatomic, acceptable and poor based on anteroposterior and lateral plain films. Delayed bone union was defined as lacking formation of callus on plain films 4 months after surgery. Non-union was defined as atrophic or hypertrophic non-union on plain films with pain at the fracture site 6 months after surgery. ${ }^{14}$ Functional status was categorized as excellent $(>92)$, good (87-92), fair $(65-86)$ and poor $(<65)$ based on the Mazur system (maximum score: 100 points). ${ }^{15}$ Traumatic arthritis was categorized as grade 1 (doubtful narrowing of joint space and osteophytes), grade 2 (definite narrowing of joint space and osteophytes), grade 3 (sharp narrowing of joint space, 
moderate multiple osteophytes, subchondral sclerosis and possible bone deformity) and grade 4 (severe narrowing of joint space, large osteophytes, marked sclerosis and definite bone deformity) based on the Lawrence system. ${ }^{16}$ Mannitol was used for at least 4 days, and antibiotics were used for 3 days after surgery. The injured limb was elevated, and bed exercise was performed if tolerated. Partial weight-bearing was allowed based on signs of union on plain films 3 months after surgery.

\section{Statistical analysis}

Statistical analysis was performed with Statistical Package for Social Science version 17.0 software (SPSS Inc, Chicago, IL, USA). Continuous variables with normal distribution were reported using mean and $\mathrm{SD}$, and compared using Student's $t$ test. Continuous variables with skewed distribution were reported using median and interquartile range, and compared using Mann-Whitney $U$ test. Categorical variables were reported with number and percentage, and compared with Chi-square test. $P$-value $<0.05$ was considered statistically significant.

\section{Results}

Participants had a median age of 65 (63-68) years, with 157 males $(68.3 \%)$ and 73 females (31.7\%). X-rays of a male patient (63 years old) with type III Pilon fracture are shown in
Figure 1. Age, sex, causes, sides and types of Pilon fractures were not different between the two groups $(P>0.05$ for all; Table 1). Patients with open fracture $(n=56)$ had the following complication rates: screw loosening $(n=2,3.6 \%)$, superficial infection $(n=6,10.7 \%)$ and deep infection $(n=3,5.4 \%)$. Patients with closed fracture $(n=174)$ had the following complication rates: screw loosening $(n=5,2.9 \%)$, superficial infection $(n=14,8.1 \%)$ and deep infection $(n=6,3.5 \%)$.

Compared with EFLIF, arthroscopy-assisted minimally invasive therapy achieved a better reduction result, bone union and Mazur system $(P<0.05$ for all; Table 2$)$. Patient satisfaction, screw loosening and infection prevalence were not different between the two groups ( $P>0.05$ for all). There was no skin necrosis in the groups. Traumatic arthritis had a significantly lower prevalence in participants with arthroscopy-assisted minimally invasive therapy than EFLIF ( $P<0.05$ for all).

\section{Discussion}

Pilon fracture occurs in the horizontal surface of distal tibia, and type III Pilon fracture is a comminuted tibial intra-articular fracture commonly with obvious displacement and soft-tissue injury. ${ }^{17}$ The therapeutic goal is to not only reconstruct the articular surface and protect soft tissue, but also to promote bone union and recover the functional status. ${ }^{18}$ Pilon fracture is so complex that its therapy poses a great challenge to surgeons. The previously used surgical
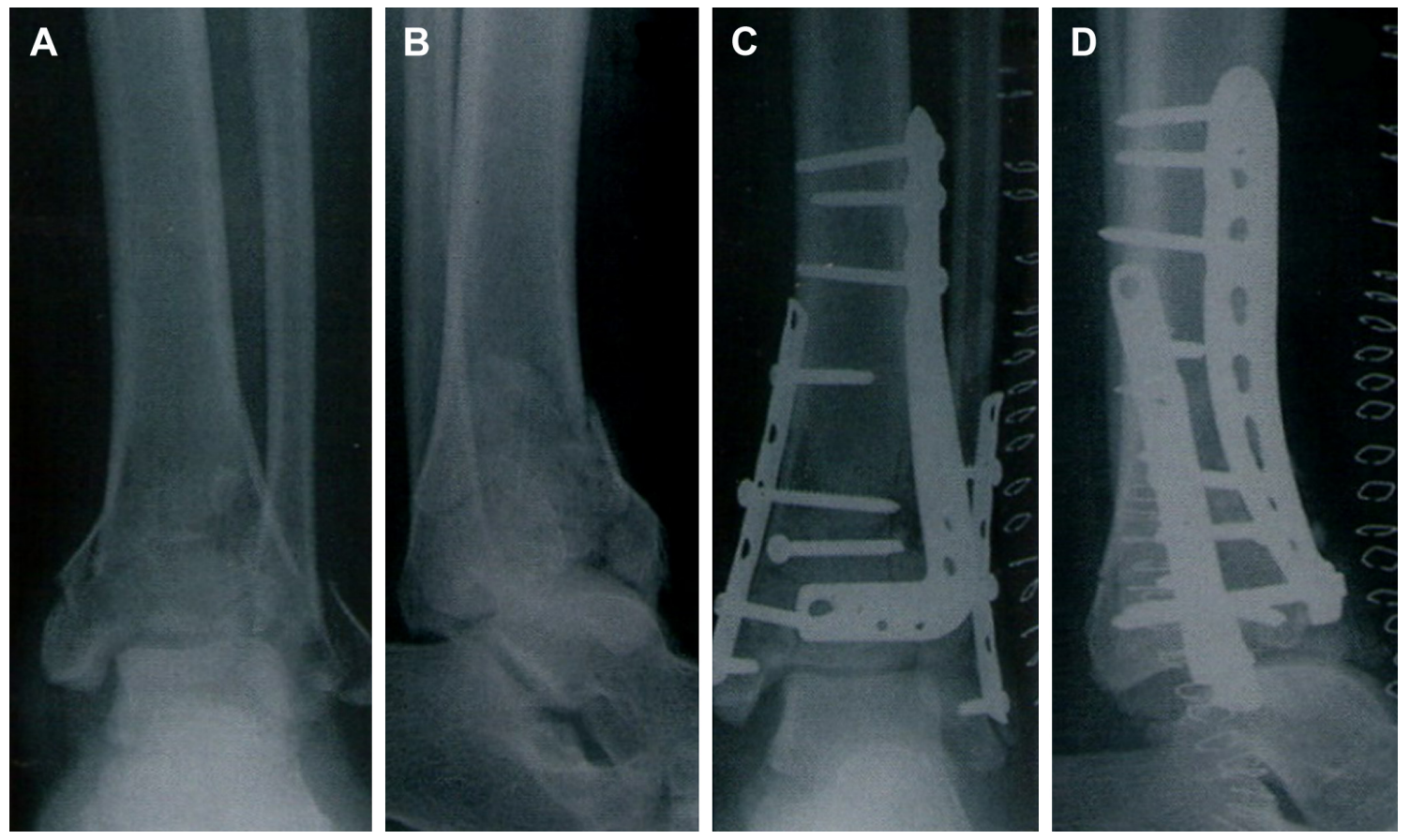

Figure I A male patient (63 years old) with type III pilon fracture.

Notes: (A) Preoperative anteroposterior X-ray; (B) Preoperative anteroposterior and lateral X-ray; (C) Postoperative anteroposterior X-ray; (D) Postoperative anteroposterior and lateral X-ray. 
Table I Participant characteristics in the two groups

\begin{tabular}{llll}
\hline Characteristics & $\begin{array}{l}\text { Group A } \\
(\mathbf{n}=\mathbf{I ~ I 5 )}\end{array}$ & $\begin{array}{l}\text { Group B } \\
(\mathbf{n}=\mathbf{I} \text { I5) }\end{array}$ & P-value \\
\hline $\begin{array}{l}\text { Age (years), median } \\
\text { (interquartile range) }\end{array}$ & $65(62-68)$ & $65(63-69)$ & 0.347 \\
$\quad$ Males, n (\%) & $81(70.4)$ & $76(66.1)$ & 0.479 \\
$\quad \begin{array}{l}\text { Females, n (\%) } \\
\text { Causes, n (\%) }\end{array}$ & $34(29.6)$ & $39(33.9)$ & \\
$\quad$ Fall accidents & $34(29.6)$ & $4 I(35.7)$ & 0.555 \\
$\quad \begin{array}{l}\text { Physical sports } \\
\text { Traffic accidents }\end{array}$ & $8(7.0)$ & $9(7.8)$ & \\
$\begin{array}{l}\text { Sides, n (\%) } \\
\text { Left }\end{array}$ & $49(63.5)$ & $65(56.5)$ & \\
$\quad$ Right & $66(57.4)$ & $63(54.8)$ & \\
Types, n (\%) & & & \\
$\quad$ Open & $27(23.5)$ & $29(25.2)$ & \\
Closed & $88(76.5)$ & $86(74.8)$ & \\
\hline
\end{tabular}

Notes: Group A: external fixation combined with limited internal fixation; group B: arthroscopy-assisted minimally invasive therapy.

therapies for Pilon fracture are ORIF and EFLIF. Because type III Pilon fracture always involves soft-tissue injury, EFLIF has been recommended as a standard therapy rather than ORIF.

Minimally invasive surgical therapy may protect soft tissue and blood supply in patients with type III Pilon

Table 2 Clinical value of the 2 surgeries

\begin{tabular}{|c|c|c|c|}
\hline Characteristics & $\begin{array}{l}\text { Group A } \\
(n=115)\end{array}$ & $\begin{array}{l}\text { Group B } \\
(n=1 \mid 5)\end{array}$ & $P$-value \\
\hline Reduction result, n (\%) & & & 0.040 \\
\hline Anatomical & $56(48.7)$ & $75(65.2)$ & \\
\hline Acceptable & $54(47.0)$ & $37(32.2)$ & \\
\hline Poor & $5(4.3)$ & $3(2.6)$ & \\
\hline Bone union, $\mathrm{n}(\%)$ & & & 0.048 \\
\hline Nonunion & I (0.9) & $0(0)$ & \\
\hline Malunion & $3(2.6)$ & I (0.9) & \\
\hline Delayed union & $10(8.7)$ & $2(1.7)$ & \\
\hline Normal union & I0I (87.8) & $112(97.4)$ & \\
\hline Screw loosening, n (\%) & $4(3.5)$ & $3(2.6)$ & 0.701 \\
\hline Mazur system, n (\%) & & & 0.036 \\
\hline Excellent & $61(53.0)$ & $80(69.6)$ & \\
\hline Good & $31(27.0)$ & $15(13.0)$ & \\
\hline Fair & $17(14.8)$ & $16(13.9)$ & \\
\hline Poor & $6(5.2)$ & $4(3.5)$ & \\
\hline Patient satisfaction, n (\%) & $102(88.7)$ & $107(93.0)$ & 0.252 \\
\hline Infection prevalence, n (\%) & & & 0.620 \\
\hline No infection & $99(86.1)$ & $102(88.7)$ & \\
\hline Superficial infection & $12(10.4)$ & $8(7.0)$ & \\
\hline Deep infection & $4(3.5)$ & $5(4.3)$ & \\
\hline Traumatic arthritis, $\mathrm{n}(\%)$ & & & 0.044 \\
\hline Grade I & $42(36.5)$ & $58(50.4)$ & \\
\hline Grade 2 & $48(41.7)$ & $46(40.0)$ & \\
\hline Grade 3 & $19(16.5)$ & $8(7.0)$ & \\
\hline Grade 4 & $6(5.2)$ & $3(2.6)$ & \\
\hline
\end{tabular}

Notes: Group A: external fixation combined with limited internal fixation; group B: arthroscopy-assisted minimally invasive therapy. fracture. Paluvadi et al have suggested that patients with distal tibial fracture have significant clinical improvement after minimally invasive plate osteosynthesis. ${ }^{19,20}$ Syed and Panchbhavi have reported that patients with Pilon fracture have significant clinical improvement after closed reduction and internal fixation with percutaneous cannulated screws. ${ }^{21}$ Ankle arthroscopy and external fixator can reconstruct the articular surface and recover the functional status to treat Pilon fracture. ${ }^{22}$ Cetik et al have successfully treated a patient with Pilon fracture using arthroscopy-assisted external fixator and minimally invasive internal osteosynthesis. ${ }^{23}$ Kralinger et al have also successfully treated a patient with distal tibial fracture using arthroscopy-assisted minimally invasive reduction and percutaneous screw fixation. ${ }^{24}$ Atesok et al have shown that as a minimally invasive technology, arthroscopy-assisted surgical therapy had high accuracy for treating Pilon fracture. ${ }^{25}$ All these results of previous studies have reminded us of the enormous potential of arthroscopyassisted minimally invasive technology in treating patients with type III Pilon fracture.

To our knowledge, very few studies have specifically compared the clinical value of arthroscopy-assisted minimally invasive therapy and EFLIF in Chinese elderly with type III Pilon fracture. It is very necessary to determine an optimal choice of surgical therapy in Chinese elderly with type III Pilon fracture. The current study showed that compared with EFLIF, arthroscopy-assisted minimally invasive therapy achieved a better reduction result, bone union and functional status, supporting that it is more effective than EFLIF in Chinese elderly with type III Pilon fracture. Meanwhile, as to the complications of surgical therapy for Pilon fracture, infection has been reported to be the most common, and its increased prevalence might be caused by high-energy injury of Pilon fracture. ${ }^{26}$ Additionally, traumatic arthritis is an important complication caused by articular comminution, sustained infection, soft-tissue injury and surgical therapy. ${ }^{1}$ In spite of the similar prevalence in infection in the groups, Chinese elderly with type III Pilon fracture developed lighter traumatic arthritis, compared with EFLIF, in the current study.

Previous studies have explored the effects of different external or internal fixation in fracture patients through the finite element model. Ramlee et al have not only developed an accurate finite element model of an ankle joint, but also observed the biomechanical stability of different external fixators in type III Pilon fractures using the finite element model. ${ }^{27}$ Meng et al have compared the biomechanical stability and postoperative impact of the mini-external 
fixation and percutaneous K-wire internal fixation on Bennett fracture by using finite element analysis. ${ }^{28}$ Wieding et al have performed the finite element analysis of osteosynthesis screw fixation in the bone stock. ${ }^{29}$ The current study applied the external and internal fixation in clinical elderly patients, and compared the effects of EFLIF and arthroscopy-assisted minimally invasive therapy on type III Pilon fracture.

One limitation requires mention. In clinical practice and research work, we tried our best to avoid the occurrence of screw loosening, but there was still screw loosening in both groups. Future studies are needed to reduce or avoid the occurrence of screw loosening.

\section{Conclusion}

The current study confirmed that compared with EFLIF, arthroscopy-assisted minimally invasive therapy for type III Pilon fracture significantly improved the reduction result, bone union and functional status, and decreased traumatic arthritis, demonstrating that arthroscopy-assisted minimally invasive therapy is an optimal choice for type III Pilon fracture in Chinese elderly.

\section{Disclosure}

The authors report no conflicts of interest in this work.

\section{References}

1. Guo Y, Tong L, Li S, Liu Z. External fixation combined with limited internal fixation versus open reduction internal fixation for Treating Ruedi-Allgower type III Pilon Fractures. Med Sci Monit. 2015;21:1662-1667.

2. Schweigkofler U, Benner S, Hoffmann R. [Pilon fractures]. Z Orthop Unfall. 2015;153(3):335-354. German.

3. Klaue K, Cronier P. [Pilon fractures]. Unfallchirurg. 2015;118(9):795-801. German.

4. Boraiah S, Kemp TJ, Erwteman A, Lucas PA, Asprinio DE. Outcome following open reduction and internal fixation of open pilon fractures. J Bone Joint Surg Am. 2010;92(2):346-352.

5. Hak DJ, Lee M, Gotham DR. Influence of prior fasciotomy on infection after open reduction and internal fixation of tibial plateau fractures. J Trauma. 2010;69(4):886-888.

6. Davidovitch RI, Elkhechen RJ, Romo S, Walsh M, Egol KA. Open reduction with internal fixation versus limited internal fixation and external fixation for high grade pilon fractures (OTA type 43C). Foot Ankle Int. 2011; 32(10):955-961.

7. Tang X, Liu L, Tu CQ, Li J, Li Q, Pei FX. Comparison of early and delayed open reduction and internal fixation for treating closed tibial pilon fractures. Foot Ankle Int. 2014;35(7):657-664.

8. Ortmaier R, Filzmaier V, Hitzl W, et al. Comparison between minimally invasive, percutaneous osteosynthesis and locking plate osteosynthesis in 3-and 4-part proximal humerus fractures. BMC Musculoskelet Disord. 2015;16:297.

9. Krettek C, Bachmann S. [Pilon fractures. Part 1: Diagnostics, treatment strategies and approaches]. Chirurg. 2015;86(1):87-101. German.
10. Krettek C, Bachmann S. [Pilon fractures. Part 2: Repositioning and stabilization technique and complication management]. Chirurg. 2015;86(2):187-201. German.

11. Ruedi TP, Allgower M. The operative treatment of intra-articular fractures of the lower end of the tibia. Clin Orthop Relat Res. 1979;138: $105-110$.

12. Marin LE, Wukich DK, Zgonis T. The surgical management of high- and low-energy tibial plafond fractures: a combination of internal and external fix-ation devices. Clin Podiatr Med Surg. 2006;23(2):423-444, vii.

13. Luo H, Chen L, Liu K, Peng S, Zhang J, Yi Y. Minimally invasive treatment of tibial pilon fractures through arthroscopy and external fixator-assisted reduction. Springerplus. 2016;5(1):1923.

14. Larsen LB, Madsen JE, Hoiness PR, Øvre S. Should insertion of intramedullary nails for tibial fractures be with or without reaming? A prospective, randomized study with 3.8 years' follow-up. J Orthop Trauma. 2004;18(3):144-149.

15. Mazur JM, SchwartzE, Simon SR. Ankle arthrodesis. Long-term follow-up with gait analysis. J Bone Joint Surg Am. 1979;61(7):964-975.

16. Lawrence RC, Felson DT, Helmick CG, et al. Estimates of the prevalence of ar-thritis and other rheumatic conditions in the United States. Part II. Arthritis Rheum. 2008;58(1):26-35.

17. McCann PA, Jackson M, Mitchell ST, Atkins RM. Complications of definitive open reduction and internal fixation of pilon fractures of the distal tibia. Int Orthop. 2011;35(3):413-418.

18. Ramlee MH, Kadir MR, Murali MR, Kamarul T. Finite element analysis of three commonly used external fixation devices for treating Type III pilon fractures. Med Eng Phys. 2014;36(10):1322-1330.

19. Paluvadi SV, Lal H, Mittal D, Vidyarthi K. Management of fractures of the distal third tibia by minimally invasive plate osteosynthesis-a prospective series of 50 patients. J Clin Orthop Trauma. 2014;5(3): 129-136.

20. Vidović D, Matejčić A, Ivica M, Jurišić D, Elabjer E, Bakota B. Minimallyinvasive plate osteosynthesis in distal tibial fractures: results and complications. Injury. 2015;46(Suppl 6):S96-S99.

21. Syed MA, Panchbhavi VK. Fixation of tibial pilon fractures with percutaneous cannulated screws. Injury. 2004;35(3):284-289.

22. Japjec M, Staresinić M, Culjak V, Vrgoc G, Sebecić B. The role of external fixation in displaced pilon fractures of distal tibia. Acta Clin Croat. 2013;52(4):478-484.

23. Cetik O, Cift H, Ari M, Comert B. Arthroscopy-assisted combined external and internal fixation of a pilon fracture of the tibia. Hong Kong Med J. 2007;13(5):403-405.

24. Kralinger F, Lutz M, Wambacher M, Smekal V, Golser K. Arthroscopically assisted reconstruction and percutaneous screw fixation of a Pilon tibial fracture. Arthroscopy. 2003;19(5):E45.

25. Atesok K, Doral MN, Whipple T, et al. Arthroscopy-assisted fracture fixation. Knee Surg Sports Traumatol Arthrosc. 2011;19(2):320-329.

26. Stavlas P, Polyzois D. Septic arthritis of the major joints of the lower limb after periarticular external fixation application: are conventional safe cor-ridors enough to prevent it? Injury. 2005;36(2):239-247.

27. Ramlee MH, Kadir MR, Murali MR, Kamarul T. Finite element analysis of three commonly used external fixation devices for treating Type III pilon fractures. Med Eng Phys. 2014;36(10):1322-1330.

28. Meng L, Zhang Y, Lu Y. Three-dimensional finite element analysis of mini-external fixation and Kirschner wire internal fixation in Bennett fracture treatment. Orthop Traumatol Surg Res. 2013;99(1):21-29.

29. Wieding J, Souffrant R, Fritsche A, Mittelmeier W, Bader R. Finite element analysis of osteosynthesis screw fixation in the bone stock: an appropriate method for automatic screw modelling. PLoS One. 2012; 7(3):e33776. 


\section{Publish your work in this journal}

Clinical Interventions in Aging is an international, peer-reviewed journal focusing on evidence-based reports on the value or lack thereof of treatments intended to prevent or delay the onset of maladaptive correlates of aging in human beings. This journal is indexed on PubMed Central, MedLine,

CAS, Scopus and the Elsevier Bibliographic databases. The manuscript management system is completely online and includes a very quick and fair peer-review system, which is all easy to use. Visit http://www.dovepress. com/testimonials.php to read real quotes from published authors.

Submit your manuscript here: http://www.dovepress.com/clinical-interventions-in-aging-journal 